\title{
Expression and prognostic significance of the apoptotic genes BCL2L13, Livin, and CASP8AP2 in childhood acute lymphoblastic leukemia
}

\author{
Yung-Li Yang a,b, Shu-Rung Lin ${ }^{c}$, Jiann-Shiuh Chen ${ }^{\mathrm{d}, \mathrm{j}}$, Shu-Wha Lin ${ }^{\mathrm{e}, \mathrm{f}}$, Sung-Liang Yu ${ }^{\mathrm{a}, \mathrm{e}, \mathrm{f}, \mathrm{g}}$, \\ Hsuan-Yu Chen ${ }^{\mathrm{h}}$, Ching-Tzu Yen ${ }^{\mathrm{f}}$, Chien-Yu Lin ${ }^{\mathrm{h}}$, Jing-Fang Lin ${ }^{\mathrm{f}}$, Kai-Hsin Lin ${ }^{\mathrm{b}}$, \\ Shiann-Tarng Jou ${ }^{b}$, Chung-Yi Hu ${ }^{f}$, Sheng-Kai Chang ${ }^{\text {, }}$, Meng-Yao Lu ${ }^{\text {b }}$, Hsiu-Hao Chang ${ }^{\text {b }}$, \\ Wan-Hui Chang ${ }^{i}$, Kuo-Sin Lin ${ }^{\mathrm{i}}$, Dong-Tsamn Lin ${ }^{\mathrm{a}, \mathrm{b}, *}$
}

\footnotetext{
a Department of Laboratory Medicine, College of Medicine, National Taiwan University, Taipei, Taiwan

b Department of Pediatrics, College of Medicine, National Taiwan University, Taipei, Taiwan

${ }^{c}$ Department of Bioscience Technology, College of Science, Chung-Yuan Christian University, Taoyuan, Taiwan

${ }^{\mathrm{d}}$ Department of Internal Medicine, College of Medicine, National Taiwan University, Taipei, Taiwan

e Department of Medical Research, College of Medicine, National Taiwan University, Taipei, Taiwan

${ }^{\mathrm{f}}$ National Taiwan University Hospital, Department of Clinical Laboratory Sciences and Medical Biotechnology, College of Medicine,

National Taiwan University, Taipei, Taiwan

g NTU Center for Genomic Medicine, College of Medicine, National Taiwan University, Taipei, Taiwan

h Institute of Statistical Science Academia Sinica, Taiwan

i Taiwan Childhood Cancer Foundation, Taipei, Taiwan

j Department of Pediatrics, National Cheng Kung University Hospital, Tainan, Taiwan
}

\section{A R T I C L E I N F O}

\section{Article history:}

Received 15 January 2009

Received in revised form 12 July 2009

Accepted 14 July 2009

\section{Keywords:}

Childhood acute lymphoblastic leukemia

(ALL)

BCL2L13

Livin

CASP8AP2

\begin{abstract}
A B S T R A C T
Improved treatment of childhood acute lymphoblastic leukemia (ALL) depends on the identification of new molecular markers that are able to predict treatment response and clinical outcome. The development of impaired apoptosis in leukemic cells is one factor that may influence their response to treatment. We investigated the expression of three apoptosis related genes, BCL2L13, CASP8AP2, and Livin, as well as their prognostic significance, in a retrospective study of 90 pediatric ALL patients diagnosed between 1996 and 2007 in Taiwan. Univariant analysis revealed that high expression of BCL2L13 was associated with inferior event-free survival and overall survival ( $p<0.001$ and 0.005 , respectively). Multivariate analysis for EFS and OS demonstrated that high expression of BCL2L13 was an independent prognostic factor for childhood ALL in this ethnic group.
\end{abstract}

(c) 2009 Elsevier Ltd. All rights reserved.

\section{Introduction}

Recent progress in the use of DNA microarrays has identified genes that regulate cell cycle control, DNA repair, and apoptosis which may also participate in disordered cell proliferation and cancer progression in leukemia [1,2]. Alterations in the basal level of expression of these genes may also affect the drug response and clinical outcome of leukemic patients. The cure rate of childhood acute lymphoblastic leukemia (ALL) has increased from 10 to $80 \%$ in the developed countries, a fact which may largely be a consequence

\footnotetext{
* Corresponding author at: Department of Laboratory Medicine and Pediatrics, National Taiwan University Hospital, College of Medicine, National Taiwan University, No. 7 Chung-San S. Rd., Sec. 1, Taipei 100, Taiwan. Tel.: +886 $223123456 x 65399$; fax: +886223224263.

E-mail address: dtlin@ntuh.gov.tw (D.-T. Lin).
}

of the stringent application of prognostic factors for risk-factordirected therapy $[3,4]$. The identification of new such gene markers is therefore important not only to gain a basic understanding of the signaling pathways that operate in leukemogenesis, but also to implement enhancements to disease classification systems and to productively target disease with novel therapies.

It has been shown that decreased apoptosis may be an important step in the acquisition of cellular drug resistance in pediatric acute leukemia. Holleman et al. used microarrays to investigate the expression of 70 apoptosis genes, and revealed that BCL2L13 expression was an independent prognostic factor [5]. Flotho et al. analyzed gene expression in diagnostic lymphoblasts, and compared the findings to minimal residual disease (MRD) levels on days 19 and 46 of remission induction therapy. They identified 17 genes that were significantly associated with MRD level. Among these, the gene coding for caspase 8 -associated protein 2 (CASP8AP2) was studied further and showed a strong correlation with prog- 
nosis [6]. Chio et al. studied the expression of Livin, a member of the IAP family of childhood ALL [7]. Unexpectedly, Livin expression was an independent prognostic factor in their cohort. These studies demonstrated an association between dysregulated apoptosis pathways and treatment prognosis, and suggested that the identified genes might serve as functionally defined risk factors for treatment stratification, in addition to those factors currently used.

If specific patterns of gene expression can be correlated with clinical features in childhood ALL, a refinement of current prognosis-based stratification systems might be possible. Thus, we analyzed BCL2L13, CASP8AP2, and Livin gene expression in the childhood ALL of a specific ethnic group, and investigated their correlation with treatment outcomes.

\section{Design and methods}

\subsection{Patients}

Viable diagnostic bone marrow (BM) or peripheral blood (PB) was obtained from 90 children who were diagnosed with ALL between July 1996 and August 2007 at National Taiwan University Hospital (NTUH) and National Cheng Kung University Hospital (NCKUH). Of these, 78 patients had been newly diagnosed with B-precursor ALL, and 12 patients with T-cell ALL. Forty-seven patients were treated with TPOG-93-ALL protocols and 43 patients were treated with TPOG-2002-ALL protocols, which are described in detail elsewhere [8,9]. The diagnosis of ALL was made based on the morphologic findings of BM aspirates, as well as on immunophenotype analyses of leukemic cells by flow cytometry. Conventional cytogenetics analyses were performed as part of the routine workup.

Patients were prospectively assigned to one of three risk groups (standard, high, and very high) based on their presenting clinical features and the biological features of their leukemic cells. Patients were considered to have standard-risk (SR) ALL if they were between 1 and 9 years old with a presenting leukocyte count less than $10 \times 10^{9}$ (cells/L) or were between 2 and 7 years old with a presenting leukocyte count between $10 \times 10^{9}$ and $50 \times 10^{9}$. Patients were considered to have high-risk (HR) ALL if they were between 1 and 9 years old with a presenting leukocyte count between $50 \times 10^{9}$ and $100 \times 10^{9}$, or between 1 and 2 or 7 and 10 years old with a presenting leukocyte count between $10 \times 10^{9}$ and $50 \times 10^{9}$. Patients with at least one of the following were assigned to the very-high-risk (VHR) group: age younger than 1 year, initial leukocyte count greater than $100 \times 10^{9}$, T-cell ALL, or presence of $B C R-A B L, M L L-A F 4$ or other $M L L$ rearrangements in pre-B ALL.

The risk-directed Taiwan Pediatric Oncology Group (TPOG) protocols consisted of multiple chemotherapeutic agents of different intensities. The treatment protocol was upgraded if complete remission was not achieved after initial induction therapy. Events were defined as any relapse, death, or secondary malignancy. This study was approved by the Medical Ethics Committee of National Taiwan University Hospital. Informed consent was obtained from the patients or their parents before sample collection.

\subsection{Methods}

\subsubsection{RNA isolation}

Mononuclear cells from bone marrow (BM) or peripheral blood (PB) were Ficollpurified and immediately stored in liquid nitrogen. Cryopreserved samples were thawed and washed in FBS-supplemented RPMI 1640 medium prior to RNA extraction. Total RNA was extracted using Trizol reagent according to the manufacturer's instructions (Invitrogen, Paisley, United Kingdom).

\subsubsection{Determination of BCL2L13, Livin and CASP8AP2 expression by comparative} real-time quantitative-reverse transcriptase polymerase chain reaction ( $Q-R T-P C R$ )

The mRNA expression levels of BCL2L13, Livin, CASP8AP2 and glyceraldehydes-3phosphate dehydrogenase (GAPDH) were measured by Q-RT-PCR using an ABI 7300 real-time PCR system (Applied Biosystems, Foster City, CA). Mature mRNAs were reverse-transcribed into cDNA using oligo-dT and random hexamers as primers by standard methods as described previously [10]. Quantitative PCR amplification of individual cDNAs was performed using the pre-developed Taqman gene expression assay for BCL2L13 (Hs00209789_m1), Livin (Hs00223384_m1) and CASP8AP2 (Hs01594281_m1)(Applied Biosystems, Foster City, CA). TaqMan endogenous control assay for the GAPDH was combined with the assay for target gene in the same reaction (Applied Biosystems). All reactions were performed in duplicate at a minimum. The $20 \mu \mathrm{l}$ PCR reaction mixture contained $12.5 \mathrm{ng}$ cDNA, $900 \mathrm{nM}$ primers, $250 \mathrm{nM}$ probe, and $1 \times$ Taqman universal master mix, combining AmpliTaq Gold ${ }^{\circledR}$ DNA Polymerase, AmpErase ${ }^{\circledR}$ UNG, dNTPs with dUTP, and optimized buffer components. After an initial incubation at $50^{\circ} \mathrm{C}$ for $2 \mathrm{~min}$, and a denaturing step at $95^{\circ} \mathrm{C}$ for $10 \mathrm{~min}$, a 2 -step PCR $\left(95^{\circ} \mathrm{C}\right.$ for $15 \mathrm{~s}$ followed by $60^{\circ} \mathrm{C}$ for $\left.1 \mathrm{~min}\right)$ was performed for 45 cycles to amplify and detect the target sequence.

The expression levels of the target genes in unknown samples were normalized standardized for expression of GAPDH and analyzed by the $\triangle \triangle \mathrm{Ct}$ method
$\left[\Delta \Delta \mathrm{Ct}=\left(\mathrm{Ct}_{\text {target gene }}-\mathrm{Ct}_{\text {GAPDH }}\right)\right.$ sample $-\left(\mathrm{Ct}_{\text {target gene }}-\mathrm{Ct}_{\mathrm{GAPDH}}\right)$ calibrator $]$. The average of $\Delta \mathrm{Ct}\left(\mathrm{Ct}_{\text {target gene }}-\mathrm{Ct}_{\mathrm{GAPDH}}\right)$ from all samples combined was defined as 0 , as the calibrator. The amplification efficiencies for target genes and GAPDH were calculated and showed the same slopes. A negative control without the templates was also included in each experiment.

\subsubsection{Statistical methods}

Comparison of baseline clinical variables across groups was made using the Fisher's exact test for categorical data. The nonparametric Mann-Whitney U-test was applied for continuous variables. A $p$-value $<0.05$ (two-sided) was considered significant.

Patients analyzed for BCL2L13 expression were initially divided into two groups according to their median level of $B C L 2 L 13$ (median $=5.91$ as cut-off point). We divided the patients into three groups of 30 patients each according to the CASPSBAP2 expression levels (5.5 and 10.5 as cut-off point). The patients were categorized into two groups according to the presence or absence of the Livin expression.

OS was calculated using the Kaplan-Meier method, and the log-rank test was used to compare differences between survival curves. OS was measured from the protocol commencement date until the date of death regardless of cause, excluding patients who were alive at last follow-up. EFS was defined only for patients who achieved complete remission, and was measured from the date of attaining CR until the date of relapse. Patients with no report of relapse by the end of the follow-up observation were censored on the date of last follow-up.

Cox proportional hazard models were constructed for EFS and OS. The following covariates were included in the full model of OS and EFS: BCL2L13 expression (low vs. high), CASP8AP2 expression (low, median and high), Livin expression (presence or absence), sex, $\mathrm{WBC}(<100,000 / \mu \mathrm{L}$ vs. $100,000 / \mu \mathrm{L})$, age ( $<10$ years vs. $>10$ years), immunophenotypes (B or T), hospital, and genetic subtypes. Stepwise backward selection was performed. All calculations were performed using the SAS software package, version 9 (SAS Inc.)

\section{Results}

\subsection{Patient characteristics (Table 1)}

The clinical characteristics of patients at the time of diagnosis are presented in Table 1 . The median age among 90 patients ( 46 boys and 44 girls) was 4.3 years (range: $0-17$ years), and their median leukocyte count was 20.0 (range: $0.2-1826$ ). The number of SR, HR, and VHR patients was 24,31 , and 35 respectively.

\subsection{The association of BCL2L13, CASP8AP2 and Livin expression level with clinical outcomes}

Patients were defined as low and high BCL2L13 as described in Section 2. The BCL2L13 expression level did not differ among the different risk groups (Table 1). Patients with lower BCL2L13 expression had better EFS $(p<0.001)$, and better OS ( $p=0.005)$ (Fig. 1$)$.

Patients were defined as low, median and high CASP8AP2 as described above. The CASP8AP2 expression level did not differ among the different risk groups (Table 1 ). The prognosis did not differ between different CASP8AP2 expression groups (Fig. 2).

As expected, approximately $21.1 \%$ of patients expressed Livin, as was reported by Choi et al. In our series, 20 patients expressed Livin and 70 patients did not. We compared EFS and OS between patients who did and did not express Livin. There was no statistically significant difference between these two groups of patients (Fig. 3).

\subsection{Multiple variable (Cox regression) analysis reveals that BCL2L13 was an independent prognostic factor}

We performed multivariable Cox regression analyses examining the correlation between EFS or OS and BCL2L13, CAP8AP2and Livin status, other known prognostic factors, and age and white count listed in Table 1. When other significant predictors of EFS were controlled for in the final model, $M L L$ gene rearrangement, initial white counts more than $100,000 / \mu \mathrm{L}$, risk groups and the expression level of $B C L 2 L 13$ were correlated with EFS (hazard ratio for $B C L 2 L 13=4.11$, $p=0.0025$ ) (Table 2). When other significant predictors of OS were controlled for in the final model, $M L L$ gene rearrangement, initial white counts more than $100,000 / \mu \mathrm{L}$, and the expression level of 
Table 1

The clinical features of patients at diagnosis and their association with three genes studied.

\begin{tabular}{|c|c|c|c|c|c|c|c|c|c|c|}
\hline & \multicolumn{3}{|l|}{ BCL2L13 } & \multicolumn{4}{|c|}{ CASP8AP2 } & \multicolumn{3}{|l|}{ Livin } \\
\hline & $\begin{array}{l}\text { Low } \\
\text { number }\end{array}$ & $\begin{array}{l}\text { High } \\
\text { number }\end{array}$ & $p$-value ${ }^{*}$ & $\begin{array}{l}\text { Low } \\
\text { number }\end{array}$ & $\begin{array}{l}\text { Median } \\
\text { number }\end{array}$ & $\begin{array}{l}\text { High } \\
\text { number }\end{array}$ & $p$-value & $\begin{array}{l}\text { Positive } \\
\text { number }\end{array}$ & $\begin{array}{l}\text { Negative } \\
\text { number }\end{array}$ & $p$-value ${ }^{*}$ \\
\hline \multicolumn{11}{|l|}{ WBC } \\
\hline$<100,000 / \mu \mathrm{L}$ & 36 & 12 & 0.462 & 24 & 21 & 23 & 0.749 & 16 & 52 & 0.771 \\
\hline$>100,000 / \mu \mathrm{L}$ & 9 & 13 & & 6 & 9 & 7 & & 4 & 18 & \\
\hline \multicolumn{11}{|c|}{ Immunophenotype } \\
\hline B & 36 & 42 & 0.118 & 23 & 24 & 27 & 0.578 & 18 & 16 & 1.000 \\
\hline $\mathrm{T}$ & & & & & & & & & & \\
\hline \multicolumn{11}{|l|}{ Age } \\
\hline$<10$ years & 33 & 32 & 1.000 & 21 & 22 & 22 & 1.000 & 16 & 49 & 0.572 \\
\hline$>10$ years & 12 & 13 & & 9 & 8 & 8 & & 4 & 21 & \\
\hline \multicolumn{11}{|l|}{ Risk groups } \\
\hline Standard risk & 14 & 10 & 0.335 & 9 & 7 & 8 & 0.929 & 7 & 17 & 0.592 \\
\hline High risk & 17 & 14 & & 11 & 11 & 9 & & 7 & 24 & \\
\hline Very high risk & 14 & 21 & & 10 & 12 & 13 & & 6 & 29 & \\
\hline \multicolumn{11}{|l|}{ Hyperdiplopid } \\
\hline Negative & 36 & 41 & 0.230 & 23 & 28 & 26 & 0.217 & 58 & 19 & 0.283 \\
\hline Positive & 9 & 4 & & 7 & 2 & 4 & & 12 & 1 & \\
\hline \multicolumn{11}{|l|}{$t(9 ; 22)$} \\
\hline Negative & 45 & 43 & 0.494 & 30 & 28 & 30 & 0.326 & 20 & 69 & 1.000 \\
\hline Positive & 0 & 2 & & 2 & 0 & 2 & & 0 & 4 & \\
\hline \multicolumn{11}{|l|}{ MLL gene } \\
\hline Negative & 45 & 41 & 0.117 & 28 & 30 & 28 & 0.54 & 20 & 66 & 0.572 \\
\hline Positive & 0 & 4 & & 2 & 0 & 2 & & 0 & 4 & \\
\hline \multicolumn{11}{|l|}{ Hospital } \\
\hline NTUH & 29 & 38 & 0.052 & 24 & 20 & 23 & 0.565 & 52 & 15 & 1.000 \\
\hline MCKUH & 16 & 7 & & 6 & 10 & 7 & & 18 & 5 & \\
\hline
\end{tabular}

* Fisher exact test.

$B C L 2 L 13$ were correlated with OS (hazard ratio for $B C L 2 L 13=3.41$, $p=0.0244$ ) (Table 3).

\subsection{Three gene signature as a predictor as outcome}

We attempted to develop a risk signature using the combination of three markers studied. The signature was CASP8AP2 $\times 0.03869+$ $B C L 2 L 13 \times 0.02747+$ Livin code $(0$ or 1$)-0.59135$. The patients with high-risk signature had inferior EFS than patients with low-risk signature ( $p=0.0084$, median $=0.463$ as cut-off point) (Fig. 4). We performed multivariable Cox regression analyses examining the correlation between EFS and other known prognostic factors, genetic types, age and white count listed in Table 1 . The results were shown in Table 4. When other significant predictors of EFS were controlled for in the final model, MLL gene rearrangement,
Table 3

Multivariate Cox regression analysis for OS.

\begin{tabular}{|c|c|c|c|}
\hline Variables & Hazard ratio (HR) & $95 \% \mathrm{HR} \mathrm{Cl}$ & $p$-value \\
\hline Livin & 0.49 & $0.11-2.29$ & 0.365 \\
\hline CASP8AP2 & 1.12 & $0.58-2.17$ & 0.738 \\
\hline BCL2L13 & 2.45 & $0.67-9.04$ & 0.178 \\
\hline$W B C>100,000 / \mu \mathrm{L}$ & 3.30 & $0.81-13.43$ & 0.095 \\
\hline B vs. T & 0.43 & $0.07-2.89$ & 0.388 \\
\hline Age $>10$ & 1.39 & $0.36-5.35$ & 0.630 \\
\hline Risk groups & 1.85 & $0.61-5.57$ & 0.277 \\
\hline Hyperdiplopid & 0 & 0 & 0.992 \\
\hline$t(9 ; 22)$ & 1.38 & $0.25-7.67$ & 0.716 \\
\hline$M L L$ gene rearrangements & 6.28 & $1.38-28.56$ & 0.017 \\
\hline \multicolumn{4}{|l|}{ Step selection } \\
\hline BCL2L13 & 3.41 & $1.17-9.93$ & 0.0244 \\
\hline$W B C>100,000 / \mu \mathrm{L}$ & 5.25 & $2.05-13.44$ & 0.0005 \\
\hline$M L L$ gene rearrangements & 8.05 & $1.99-32.54$ & 0.0034 \\
\hline
\end{tabular}

Table 2

Multivariate Cox regression analysis for EFS.

\begin{tabular}{llcl}
\hline Variables & Hazard ratio (HR) & $95 \% \mathrm{HR} \mathrm{Cl}$ & $p$-value \\
\hline Livin & 0.73 & $0.24-2.25$ & 0.587 \\
CASP8AP2 & 1.12 & $0.53-2.00$ & 0.695 \\
BCL2L13 & 3.25 & $1.09-9.72$ & 0.035 \\
WBC $>100,000 / \mu \mathrm{L}$ & 2.77 & $0.89-8.60$ & 0.079 \\
B vs. T & 0.74 & $0.18-3.03$ & 0.679 \\
Age $>10$ & 1.39 & $0.49-3.95$ & 0.537 \\
Risk groups & 2.02 & $0.82-4.98$ & 0.127 \\
Hyperdiplopid & 0.44 & $0.06-3.52$ & 0.44 \\
$t(9 ; 22)$ & 2.65 & $0.48-14.52$ & 0.261 \\
MLL gene rearrangements & 5.75 & $1.42-23.23$ & 0.014 \\
Step selection & & & \\
BCL2L13 & 4.11 & $1.64-10.30$ & 0.0025 \\
WBC $>100,000 / \mu L$ & 2.72 & $1.02-7.26$ & 0.0452 \\
Risk groups & 2.28 & $1.04-4.97$ & 0.0386 \\
MLL gene rearrangements & 5.75 & $1.45-17.55$ & 0.0110 \\
\hline
\end{tabular}

Table 4

Multivariate Cox regression analysis for EFS using three gene signature as a parameter.

\begin{tabular}{llcl}
\hline Variables & Hazard ratio (HR) & $95 \% \mathrm{HR} \mathrm{Cl}$ & $p$-value \\
\hline Three gene signature & 2.68 & $1.07-6.70$ & 0.035 \\
WBC $>100,000 / \mu \mathrm{L}$ & & $0.78-6.83$ & 0.129 \\
$\mathrm{~B}$ vs. T & 0.54 & $0.15-1.99$ & 0.356 \\
Age $>10$ & 1.47 & $0.53-4.07$ & 0.461 \\
Risk groups & 2.42 & $1.00-5.88$ & 0.051 \\
Hyperdiplopid & 0.47 & $0.06-3.77$ & 0.478 \\
$t(9 ; 22)$ & 2.89 & $0.53-15.72$ & 0.220 \\
$M L L$ gene rearrangements & 6.98 & $1.78-27.30$ & 0.005 \\
Step selection & & & \\
Three gene signature & 2.85 & $1.21-6.70$ & 0.0163 \\
WBC $>100,000 / \mu \mathrm{L}$ & 6.36 & $1.83-22.08$ & 0.0036 \\
$M L L$ gene rearrangements & 3.51 & $1.82-6.76$ & 0.0002 \\
\hline
\end{tabular}



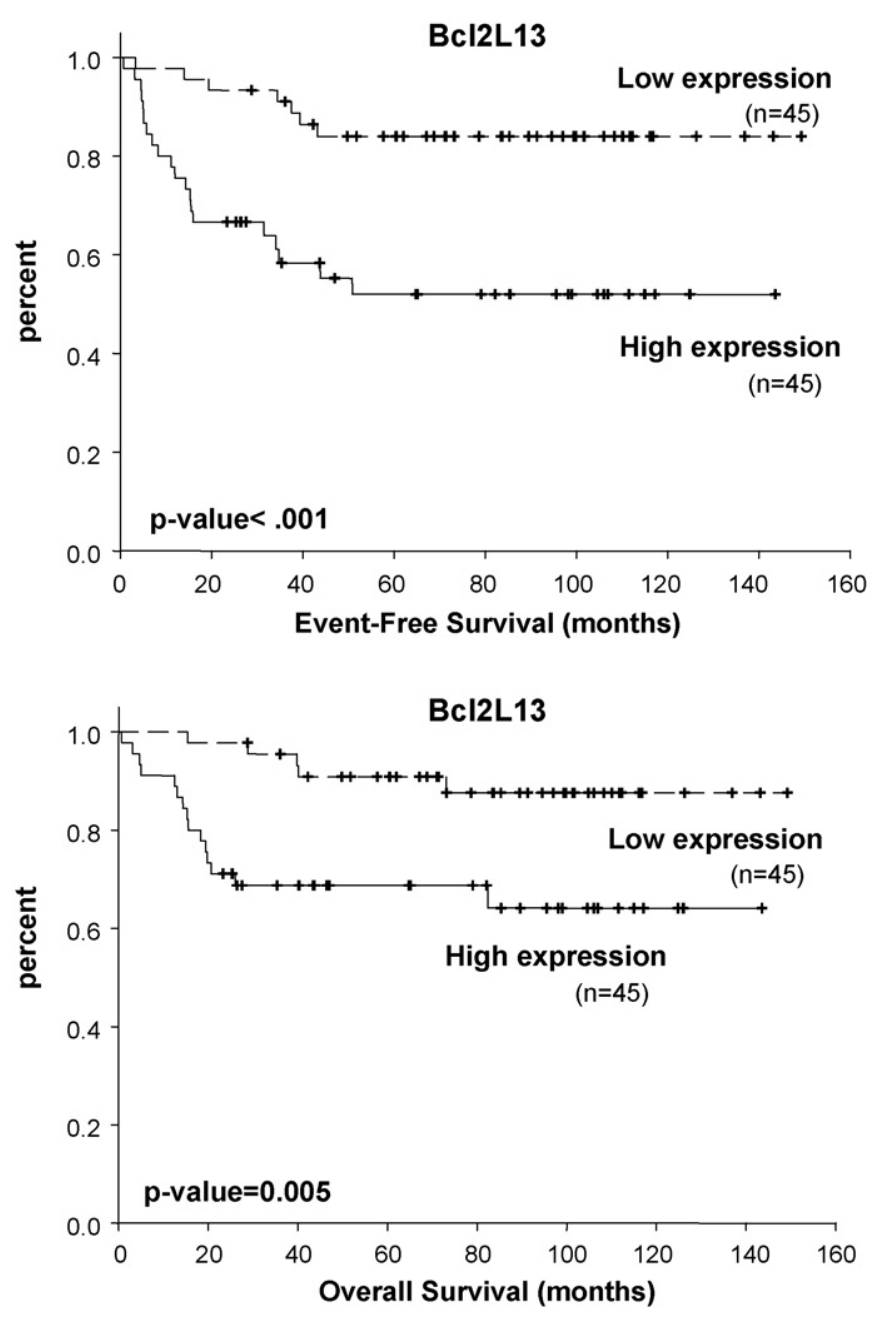

Fig. 1. Patients with lower BCL2L13 expression had better EFS $(p<0.001)$, and better OS $(p=0.005)$.

risk groups and the three gene signature were correlated with EFS (hazard ratio for three gene signature $=2.85, p=0.0163$ ).

\section{Discussion}

The principal goal of this study was to measure the expression, in pediatric ALL patients, of three genes involved in apoptotic pathways, and to determine whether these showed any correlation with clinical outcomes. In our study, higher expression of BCL2L13 was associated with inferior EFS and OS. The expressions of CASP8AP2 and Livin were not associated with clinical outcomes in our cohort. We also attempted to develop a three gene signature to predict the clinical outcome in this study cohort.

$B C L 2 L 13$ is a member of the BCL-2 family, and has pro-apoptotic activity [11]. Our results were consistent with those of Holleman et al., who reported that high expression of BCL2L13 was associated with inferior outcome, a finding that was validated by another cohort [5]. In theory, impaired apoptosis of leukemia cells might allow them to resist chemotherapy, and thus low expression of BCL2L13 would be expected to indicate a better prognosis following cancer treatment. These apparently conflicting results suggest that BCL2L13 may have a different apoptotic role in childhood ALL in comparison to its behavior in the cell lines that were used to characterize its apoptotic functions. One possible mechanism to explain this difference is alternative splicing, which is known to generate both anti- and pro-apoptic variants of apoptosis genes such as Apaf-1 and Livin [12-14]. The explanation for the finding that high expression of $B C L 2 L 13$ was associated with inferior treatment response will thus require further study.

We attempted to develop a risk signature by the combination of three genes studied. We can use this signature to predict the clinical outcome in this cohort. After multivariate regression including this signature and other known risk factor, this signature can predict the EFS but not OS. However, the $p$-value and hazard ratio were less powerful than the expression of BCL2L13 alone (HR: 2.81 and $p=0.0163$ vs. HR: 4.11 and $p=0.0025$ for EFS). This may be due to the clinical significance of the expression BCL2L13 but not Livin and CASP8AP2 in this ethical group. A larger prospective study cohort may be needed to validate this finding.

Genome-wide, gene-expression profiling offers a powerful new approach to the study of leukemia cell biology and potentially provides a new molecular classification of leukemia [15-19]. Although our sample size was small, the results differed in some respects from those previously reported. First, we found BCL2L13 expression to predict survival in the same way as previously reported. We did not find any clinical significance of CASP8AP2 and Livin individually. Several recent studies attempted to identify prognostically relevant genes in ALL by correlating in vitro drug sensitivities or treatment outcomes to chemotherapy drugs with gene expression profiles on microarrays $[2,20,21]$. Although several genes were identified, and were subsequently confirmed independently in patient populations, there was little overlap between gene expression signatures and established subgroups of patients, such as $t(12 ; 21)$, hyperdiploid BP-ALL, or T-cell ALL, or with established drug resistance genes. Catchpoole and colleagues [22] examined the set of 14 genes that Floth et al. [23] recently identified. The results were not
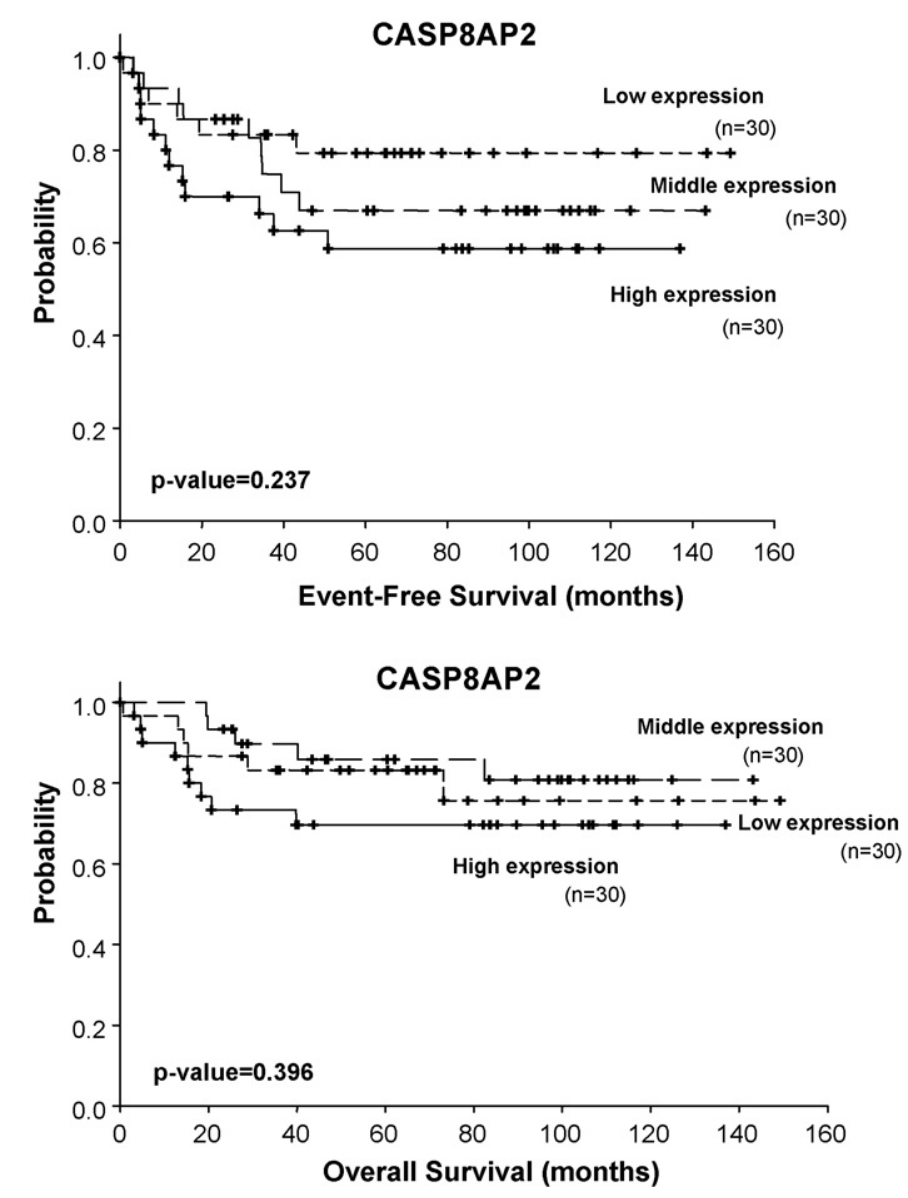

Fig. 2. The EFS and OS did not differ between different CASP8AP2 expression groups. 

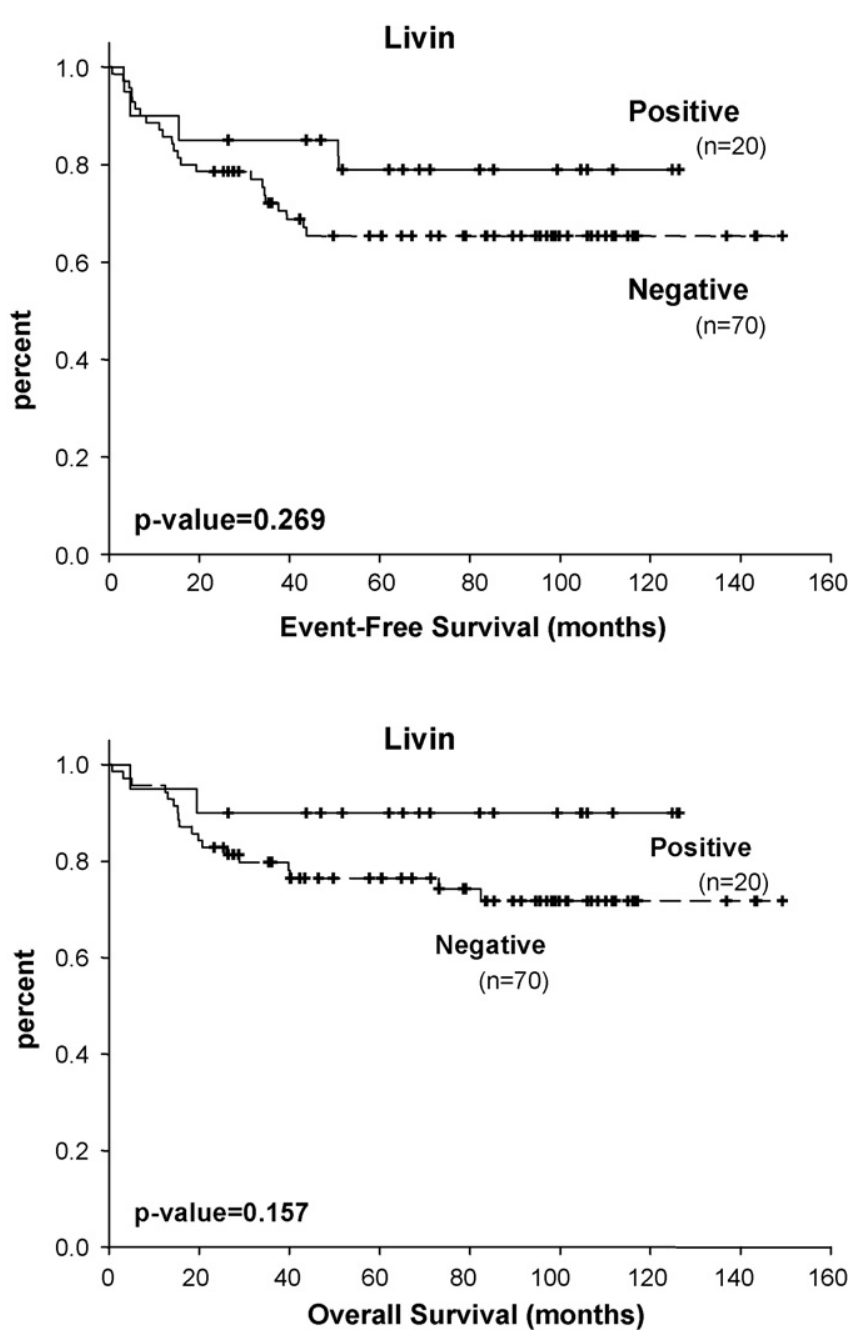

Fig. 3. There was no statistically significant difference for EFS and OS between these two groups of patients with Livin expression or not.

in agreement with the original report, suggesting that treatment outcome may be influenced by the other factors, such as pharmacogenentics, the intensity of chemotherapy, and the gene expression of primary leukemia cells. The value of gene expression profiles as

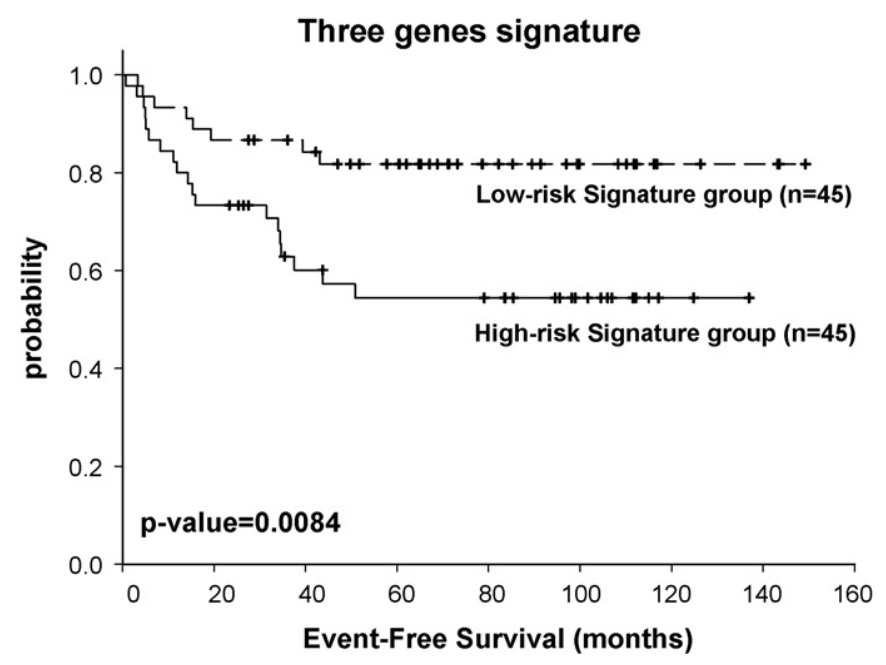

Fig. 4. The patients with high-risk signature had inferior EFS than patients with low-risk signature. prognostic indicators depends on the treatment regimen. In fact, this caveat applies to any prognostic factor.

Over the past $10-20$ years, chromosomal translocation has also emerged as an extremely important prognostic factor and means to assign patients to protocols. However, the importance of even the $t(12 ; 21)$ event remains under debate. For example, two large prospective studies focused on the prognostic impact of $t(12 ; 21)$ but reached different conclusions [24,25]. If more molecular prognostic factors can be found, it might be possible to provide accurately tailored individualized chemotherapy regimens. Despite this, the number of genes identified as being able to predict clinical outcome in ALL remains small. For examples, Cario et al. reported that expression of MADL2 was associated with MRD on week 12 in the BFM2000 study [26]. MADL2 was one of 14 genes identified by Flotho et al. [2]. Low expression of TTK (a gene encoding a kinase involved in cellcycle regulation) was identified by two groups [26,27]. Searching for genes related to treatment response across different regimens might provide clues about general mechanisms that regulate drug sensitivity in leukemic cells.

In summary, in our retrospective studies, BCL2L13 expression was an independent prognostic factor in childhood ALL. Upon confirmation of their prognostic significance in a larger ALL population, BCL2L13 may be incorporated into a new classification system. Furthermore, these genes, or other genes related to treatment failure, might themselves represent molecular targets allowing ALL cells to be sensitized to chemotherapy drugs.

\section{Conflict of interest}

The authors declare no competing financial interests.

\section{Acknowledgements}

We would like to thank all the patients and their parents who participated in this study. We also acknowledge TPOG for data collection and management. This work was supported by NTUH96-022 and Mr. Chang Han-Sen's research fund for pediatric blood disease.

Contributions. Yung-Li Yang and Shu-Rung Lin contributed equally to this article.

\section{References}

[1] Holleman A, den Boer ML, Kazemier KM, Janka-Schaub GE, Pieters R. Resistance to different classes of drugs is associated with impaired apoptosis in childhood acute lymphoblastic leukemia. Blood 2003;102:4541-6.

[2] Flotho C, Coustan-Smith E, Pei D, et al. A set of genes that regulate cell proliferation predicts treatment outcome in childhood acute lymphoblastic leukemia. Blood 2007;110:1271-7.

[3] Pui CH, Evans WE. Treatment of acute lymphoblastic leukemia. N Engl J Med 2006;354:166-78.

[4] Pui CH, Robison LL, Look AT. Acute lymphoblastic leukaemia. Lancet 2008;371:1030-43.

[5] Holleman A, den Boer ML, de Menezes RX, et al. The expression of 70 apoptosis genes in relation to lineage, genetic subtype, cellular drug resistance, and outcome in childhood acute lymphoblastic leukemia. Blood 2006;107:769-76.

[6] Flotho C, Coustan-Smith E, Pei D, et al. Genes contributing to minimal residual disease in childhood acute lymphoblastic leukemia: prognostic significance of CASP8AP2. Blood 2006; 108:1050-7.

[7] Choi J, Hwang YK, Sung KW, et al. Expression of Livin, an antiapoptotic protein, is an independent favorable prognostic factor in childhood acute lymphoblastic leukemia. Blood 2007;109:471-7.

[8] Liang DC, Hung IJ, Yang CP, et al. Unexpected mortality from the use of $E$. coli L-asparaginase during remission induction therapy for childhood acute lymphoblastic leukemia: a report from the Taiwan Pediatric Oncology Group. Leukemia 1999;13:155-60.

[9] Lin WY, Liu HC, Yeh TC, Wang LY, Liang DC. Triple intrathecal therapy without cranial irradiation for central nervous system preventive therapy in childhood acute lymphoblastic leukemia. Pediatr Blood Cancer 2008;50:523-7.

[10] Yu IS, Lin SR, Huang CC, et al. TXAS-deleted mice exhibit normal thrombopoiesis, defective hemostasis, and resistance to arachidonate-induced death. Blood 2004;104:135-42. 
[11] Kataoka T, Holler N, Micheau O, et al. Bcl-rambo, a novel Bcl-2 homologue that induces apoptosis via its unique C-terminal extension. J Biol Chem 2001;276:19548-54.

[12] Benedict MA, Hu Y, Inohara N, Nunez G. Expression and functional analysis of Apaf-1 Isoforms. Extra WD-40 repeat is required for cytochrome $\mathrm{c}$ binding and regulated activation of procaspase-9. J Biol Chem 2000;275:8461-8.

[13] Seol D-W, Billiar TR. A caspase-9 variant missing the catalytic site is an endogenous inhibitor of apoptosis. J Biol Chem 1999;274:2072-6.

[14] Nachmias B, Ashhab Y, Bucholtz V, et al. Caspase-mediated cleavage converts Livin from an antiapoptotic to a proapoptotic factor: implications for drugresistant melanoma. Cancer Res 2003;63:6340-9.

[15] Moos PJ, Raetz EA, Carlson MA, et al. Identification of gene expression profiles that segregate patients with childhood leukemia. Clin Cancer Res 2002;8:3118-30.

[16] Fine BM, Stanulla M, Schrappe M, et al. Gene expression patterns associated with recurrent chromosomal translocations in acute lymphoblastic leukemia. Blood 2004; 103:1043-9.

[17] Ross ME, Zhou X, Song G, et al. Classification of pediatric acute lymphoblastic leukemia by gene expression profiling. Blood 2003;102:2951-9.

[18] Yeoh EJ, Ross ME, Shurtleff SA, et al. Classification, subtype discovery, and prediction of outcome in pediatric acute lymphoblastic leukemia by gene expression profiling. Cancer Cell 2002;1:133-43.

[19] Ferrando AA, Neuberg DS, Staunton J, et al. Gene expression signatures define novel oncogenic pathways in T cell acute lymphoblastic leukemia. Cancer Cell 2002;1:75-87.
[20] Holleman A, Cheok MH, den Boer ML, et al. Gene-expression patterns in drugresistant acute lymphoblastic leukemia cells and response to treatment. N Engl J Med 2004;351:533-42.

[21] Lugthart S, Cheok MH, den Boer ML, et al. Identification of genes associated with chemotherapy crossresistance and treatment response in childhood acute lymphoblastic leukemia. Cancer Cell 2005;7:375-86.

[22] Catchpoole D, Guo D, Jiang H, Biesheuvel C. Predicting outcome in childhood acute lymphoblastic leukemia using gene expression profiling: Prognostication or protocol selection? Blood 2008;111:2486-a-7-a.

[23] Flotho C, Coustan-Smith E, Pei D, et al. A set of genes that regulate cell proliferation predict treatment outcome in childhood acute lymphoblastic leukemia. Blood 2007.

[24] Loh ML, Goldwasser MA, Silverman LB, et al. Prospective analysis of TEL/AML1positive patients treated on Dana-Farber Cancer Institute Consortium Protocol 95-01. Blood 2006;107:4508-13.

[25] Rubnitz JE, Wichlan D, Devidas M, et al. Prospective analysis of TEL gene rearrangements in childhood acute lymphoblastic leukemia: a Children's Oncology Group study. J Clin Oncol 2008;26:2186-91.

[26] Cario G, Stanulla M, Fine BM, et al. Distinct gene expression profiles determine molecular treatment response in childhood acute lymphoblastic leukemia. Blood 2005;105:821-6.

[27] Chiaretti S, Li X, Gentleman R, et al. Gene expression profile of adult T-cell acute lymphocytic leukemia identifies distinct subsets of patients with different response to therapy and survival. Blood 2004;103:2771-8. 